\title{
Cerambycidae (Coleoptera) coletados na Venezuela na copa de Matayba (Sapindaceae) e Vochysia (Vochysiaceae)
}

\author{
Ubirajara R. Martins ${ }^{1,3}$ \& Maria Helena M. Galileo ${ }^{2,3}$
}

\begin{abstract}
${ }^{1}$ Museu de Zoologia, Universidade de São Paulo. Caixa Postal 42494, 04218-970 São Paulo-SP, Brasil.
${ }^{2}$ Museu de Ciências Naturais, Fundação Zoobotânica do Rio Grande do Sul. Caixa Postal 1188, 90001-970, Porto Alegre-RS, Brasil. ${ }^{3}$ Bolsista do CNPq.
\end{abstract}

\begin{abstract}
Cerambycidae (Coleoptera) collected in Venezuela at the canopy of Matayba (Sapindaceae) and Vochysia (Vochysiaceae). Cerambycidae collected in Surumoni, Amazonas, Venezuela, with help of a crane, made with interception and light traps in the canopy of Matayba guianensis Aubl and Vochysia sp. resulted in new records for 14 species and descriptions of four new species: Erythropterus urucuri sp. nov. (Heteropsini), Eriphus rubellus sp. nov. (Trachyderini),
\end{abstract} Lissonotus kuaiuba sp. nov. (Lissonotini) and Acyphoderes itaiuba sp. nov. (Rhinotragini).

KEYwords. Canopy; Cerambycidae; new records; new species; Venezuela.

Resumo. Cerambycidae coletados em Surumoni, Amazonas, Venezuela, com o auxílio de uma grua, por armadilha de interceptação de vôo e armadilha luminosa nas copas de Matayba guianensis Aubl e Vochysia sp. resultaram em novos registros para 14 espécies e descrição de quatro novas: Erythropterus urucuri sp. nov. (Heteropsini), Eriphus rubellus sp. nov. (Trachyderini), Lissonotus kuaiuba sp. nov. (Lissonotini) e Acyphoderes itaiuba sp. nov. (Rhinotragini).

Palavras-Chave. Cerambycidae; dossel; novas espécies; novos registros; Venezuela.

Em 1998-1999, recebemos de Susan Kirmse, da Universidade de Leipzig, Alemanha, material de Cerambycidae coletado na Venezuela, Amazonas, Distrito de Alto Orinoco, Surumoni ( $\left.3^{\circ} 10^{\prime} \mathrm{N}, 65^{\circ} 40^{\prime} \mathrm{W}\right)$.

O material foi coletado nas copas de Matayba guianensis Aubl (Sapindaceae) e Vochysia sp. (Vochysiaceae), com armadilha de interceptação de vôo e com armadilha luminosa, situadas num guindaste a $40 \mathrm{~m}$ de altura. Os Cerambycidae diurnos estavam alimentado-se das flores de M. guianensis.

As abreviaturas utilizadas por Kirmse nas etiquetas dos exemplares correspondem a guindaste (KRAN), armadilha de interceptação de vôo (LEKL), armadilha luminosa (LF) e Matayba guianensis (vd).

Mencionamos novos registros para a Venezuela de 18 espécies ainda não assinaladas para esse país de acordo com Monné \& Hovore (2003) e descrevemos quatro espécies novas, todas de Surumoni.

As siglas mencionadas no texto correspondem a: Facultad de Agronomia, Universidad Central de Venezuela, Maracay (FAUV), Museu de Ciências Naturais, Fundação Zoobotânica do Rio Grande do Sul, Porto Alegre (MCNZ), Museu Nacional, Universidade Federal do Rio de Janeiro, Rio de Janeiro (MNRJ) e Museu de Zoologia, Universidade de São Paulo, São Paulo (MZSP).

\section{Heteropsini \\ Erythropterus urucuri sp. nov.}

(Fig. 1)

Vértice, antenas, pernas, mesosterno, metasterno e urosternitos, pretos; protórax e élitros (exceto ápices pretos), avermelhados. Escutelo preto ou avermelhado. Fronte alongada, pontuada e esparsamente pubescente. Genas com metade do comprimento dos lobos oculares inferiores. Antenas dos machos atingem o quarto apical dos élitros e, nas fêmeas, alcançam o terço apical. Escapo densamente pontuado. Antenômero III fortemente bicarenado na face superior; comprimento cerca de dois terços mais longo que o IV. Antenômeros VI-X projetados no ângulo externo. Protórax mais largo no terço posterior e gradualmente arredondado para frente e para a borda posterior; a constrição anterior mais estreita que a posterior. Pronoto com pontuação alveolada densa e rasa. Élitros com pontuação densa e rasa; úmeros projetados. Extremidades elitrais transversalmente truncadas. Metafêmures dos machos pouco mais longos que os das fêmeas, aproximam-se dos ápices dos élitros, nas fêmeas atingem o quarto apical; finamente carenados no pedúnculo. Metatíbias carenadas. Face ventral do corpo pubescente.

Dimensões em mm, respectivamente macho/fêmea. Comprimento total, 8,1-8,3/7,6; comprimento do protórax, 1,8$1,9 / 1,7$; maior largura do protórax, 1,7-1,7/1,6; comprimento do élitro, 5,8-6,3/5,1; largura umeral, 1,9-1,8/2,0.

Holótipo macho, procedente da VENEZUELA, Amazonas: Surumoni, 04.X.1997, S. Kirmse col., coletado com armadilha de interceptação de vôo, em guindaste sobre a copa de Matayba guianensis (FAUV). Parátipos - mesma procedência do holótipo, macho, 20.IX.1997, S. Kirmse col. coletado com armadilha de interceptação de vôo, em guindaste sobre a copa de M. guianensis (MZSP); macho, 26.IX.1997, S. Kirmse col. coletado com armadilha de interceptação de vôo, em guindaste sobre a copa de M. guianensis (MZSP) ; macho, 27.IX.1997, Morawetz col., em flores de Matayba guianensis (MZSP); fêmea, 28.IX.1997, S. Kirmse col. (MCNZ); fêmea, 30.IX.1997, S. Kirmse col., coletado com armadilha de interceptação de vôo, em 
guindaste sobre a copa de $M$. guianensis (MZSP).

Discussão. Erythropterus urucuri sp. nov. distingue-se de E. amabilis Melzer, 1934 pela fronte avermelhada ou com região occipital preta; pelo protórax avermelhado; pela pontuação do pronoto mais rasa. Em E. amabilis a cabeça é inteiramente preta, o protórax é preto e o pronoto tem pontuação mais profunda. Além disso, a distribuição geográfica das duas espécies é diferente, E. amabilis ocorre no sudeste e sul do Brasil, Paraguai e Argentina (Misiones) e E.urucuri está registrada, até o momento, para a Amazônia.

Etimologia. Tupi, urucuri = tinta vermelha, alusivo à coloração corporal.

\section{Trachyderini \\ Eriphus rubellus sp. nov.}

(Fig. 2)

Cabeça, protórax, pernas e face ventral do corpo, vermelhas; antenas avermelhado-escuras; élitros vermelhos, com faixa preta, sutural, inicia perto do escutelo e termina no sexto apical que é ocupado por faixa transversal preta; a faixa preta sutural é mais larga no meio e para os lados apresenta pequena mancha preta. Na fêmea (Fig. 2), a faixa preta inicia-se mais para trás e quase não se alarga no meio. Em vista lateral, os élitros têm uma faixa longitudinal preta, estreita, do terço anterior à extremidade. Superfície da cabeça microesculturada $(40 \mathrm{x}) \mathrm{com}$ pontuação rasa no vértice. Tubérculo lateral do protórax aguçado. Pronoto microesculturado, com pontos rasos, mais concentrados nos lados. Prosterno pontuado nos dois sexos. Processo prosternal truncado. Élitros microesculturados e pontuados; os pontos maiores e mais pronunciados no terço basal; duas costas em cada élitro. Extremidades elitrais transversalmente truncadas. Fêmures evidentemente pontuados, principalmente na metade apical. Extremidades dos metafêmures com espículo no lado interno. Tíbias pontuadas; pontos menores que os dos fêmures e mais concentrados nas bases. Mesepimeros opacos, pontuados. Metasterno brilhante, com pontos grandes. Urosternitos finamente pontuados e esparsamente pubescentes.

Dimensões em mm, respectivamente macho/fêmea. Comprimento total, 12,2/11,2; comprimento do protórax, 2,7/ 2,5; maior largura do protórax, 3,2/2,9; comprimento do élitro, $8,5 / 7,9$; largura umeral, 3,4/3,3.

Holótipo fêmea proveniente da Venezuela, Amazonas: Surumoni, 26.IX.1997, Morawetz col., em guindaste sobre a copa de Matayba guianensis (MZSP). Parátipo macho, mesma localidade do holótipo, 4.X.1997, S. Kirmse col., coletado com armadilha de interceptação de vôo, em guindaste sobre a copa de M. guianensis (FAUV).

Discussão. Pela chave para as espécies de Eriphus publicada por MonNÉ \& Fragoso (1996), E. rubellus sp. nov. é separada no primeiro item, junto com E. cardinalis Monné \& Fragoso, 1996: corpo predominantemente vermelho, apenas o quinto distal dos élitros enegrecido. Distingue-se pelas pernas vermelhas; pelos élitros com faixa preta sutural; pelas antenas castanho-avermelhadas; pelo ápice dos élitros transversalmente truncados; pelo metasterno brilhante; pelos metafêmures com único espinho apical interno. Em $E$. cardinalis as pernas são pretas; os élitros apresentam duas faixas longitudinais pretas, uma sutural e uma marginal, além das extremidades ocupadas por faixa preta; antenas pretas; ápices dos élitros arredondados; metasterno fosco e metafêmures com dois espinhos apicais.

O colorido avermelhado e a faixa preta sutural nos élitros também existem em E. purpuratus Chevrolat, 1862, que ocorre no Brasil meridional, Paraguai e Argentina. E. rubellus distingue-se pelas antenas, pernas e face ventral do corpo vermelhas; pelo pronoto unicolor; pelos élitros com faixa lateral e extremidades pretas e pelo metasterno brilhante e grosseiramente pontuado. Em E. purpuratus as antenas, pernas e face ventral do corpo são pretas; o pronoto tem mancha preta desenvolvida soldada à base; os élitros não têm faixa preta lateral nem extremidades pretas e o metasterno é muito fina e muito densamente pontuado.

\section{Rhinotragini \\ Acyphoderes itaiuba sp. nov.}

(Fig. 3)

Cabeça preta, sem carena longitudinal, com pubescência serícea, dourada, na fronte. Entre os lobos oculares superiores, uma estreita faixa sem pubescência ladeada por pubescência amarelo-dourada. Fronte muito estreita, sulcada entre os olhos. Lobos oculares inferiores tão distantes entre si quanto cerca do diâmetro do antenômero III. Antenas pretas, atingem a região posterior do metasterno. Protórax preto, oblongooval, desarmado aos lados. Pronoto sem calosidades; com duas faixas transversais de pêlos amarelo-dourados junto às margens anterior e posterior: a primeira interrompida no nível do meio e a segunda, contínua. Pontuação pronotal densa, exceto na parte centro-anterior. Prosterno sem tubérculo e com a metade posterior pubescente. Processo mesosternal tão largo quanto metade de uma mesocoxa. Escutelo revestido por densa pubescência amarelo-dourada. Élitros pretos na base e ao longo das margens lateral e sutural; a região dorsal vítrea, amarelada, com pontos diminutos. Extremidades elitrais arredondadas; atingem o meio do urosternito III. Pernas anteriores e médias pretas. Protíbias com pêlos curtos e densos no lado posterior. Metafêmures amarelados no pedúnculo, avermelhados na clava, atingem aproximadamente a borda apical do urosternito II. Metatíbias avermelhadas. Metatarsômero I avermelhado e os demais pretos. Abdômen avermelhado com o primeiro urosternito enegrecido nos lados; último urosternito com duas áreas longitudinais notavelmente elevadas.

Variabilidade. A pubescência pronotal é variável; em dois exemplares, a faixa transversal junto à borda anterior está restrita aos lados.

Dimensões em mm, macho. Comprimento total, 16,7-17,7; comprimento do protórax, 3,1-3,2; maior largura do protórax, 2,8-3,0; comprimento do élitro, 8,9-9,0; largura umeral, 3,4-3,6. 



Figs. 1-4. 1, Erythropterus urucuri sp. nov., parátipo fêmea; 2, Eriphus rubellus sp. nov., holótipo fêmea; 3, Acyphoderes itaiuba sp. nov., holótipo macho; 4, Lissonotus kuaiuba sp. nov., parátipo fêmea. 
Holótipo macho procedente da Venezuela, Amazonas: Surumoni, 4.X.1997, S. Kirmse col., coletado com armadilha de interceptação de vôo, em guindaste sobre a copa de Matayba guianensis (FAUV). Parátipos: 2 machos, Venezuela, Amazonas: Surumoni, 26.IX.1997, Morawetz col., em flores de M. guianensis (MNRJ, MZSP).

Discussão. Acyphoderes itaiuba sp. nov. não tem nenhuma espécie sul-americana assemelhada. Como em A. crinita (Klug, 1825), o pronoto não tem carenas demarcadas; separa-se pelo pronoto glabro com pubescência dourada junto dos frisos anterior e posterior, pelas pernas posteriores e abdômen vermelho-alaranjados.

Etimologia. Tupi, itaiuba $=$ ouro, alusivo à faixa de pubescência serícea dourada da fronte, do pronoto e do escutelo.

\section{Lissonotini \\ Lissonotus kuaiuba sp. nov. (Fig. 4)}

Macho. Cabeça preta. Antenas pretas, menos no lado interno do escapo com mancha avermelhada, pouco contrastante. Pronoto preto com mancha pouco contrastante, avermelhada, transversal, no meio da metade anterior e mancha, mais desenvolvida, na metade apical. Élitros pretos; cada um com mancha amarelada, transversal, central, que não alcança a margem ou a sutura. Fêmures vermelhos com ápice preto; essa coloração preta é mais extensa nos profêmures e gradualmente menos extensa nos meso- e metafêmures. Tíbias vermelhas com ponta preta. Prosterno e mesosterno pretos. Mesepisternos mais avermelhados. Base do metasterno enegrecida em pequena extensão e avermelhado no restante da superfície. Urosternitos avermelhados. Antenas acentuadamente serradas, antenômeros VI-X fortemente expandidos para o lado externo. Antenômero XI mais longo que o X. Extremidades elitrais obliquamente truncadas.

Fêmea (Fig. 4). Pronoto preto. Mancha amarelada central dos élitros menor, distante da margem e da sutura. Porção preta apical dos fêmures mais reduzida. Metasterno quase inteiramente preto, apenas mais avermelhado láteroposteriormente. Antenas ultrapassam o meio dos élitros. Flagelômeros apicais fortemente angulosos no lado externo.

Dimensões em mm, respectivamente macho/fêmea. Comprimento total, 13,5/13,4; comprimento do protórax, 3,5/ 3,6 ; maior largura do protórax, 4,5/4,7; comprimento do élitro, $8,6 / 8,4$; largura umeral, 5,0/4,9.

Holótipo macho procedente da Venezuela, Amazonas: Surumoni, 22.XI.1997, Kirmse col., em "blüten" (=inflorescência) de Vochysia, "ca. 17:30" (FAUV). Parátipo fêmea, com os mesmos dados do holótipo (MZSP).
Discussão. São raras as espécies de Lissonotus com faixa amarelada transversal no meio dos élitros. Uma dessas espécies é L.f.flavocinctus Du Pont, 1836, cuja forma típica ocorre na Colômbia e na Venezuela. L. kuaiuba sp. nov. difere pelo colorido vermelho do abdômen e pelas antenas do macho mais curtas. A faixa amarelada transversal dos élitros é contínua nos exemplares examinados de L. flavocinctus enquanto que em L. kuaiuba, apresenta-se reduzida e não toca as margens.

Difere de L. zellibori Tippmann, 1953, que também apresenta faixa transversal amarelada nos élitros e antenas do macho curtas, pelo protórax predominantemente preto e, principalmente, pelos ápices dos élitros sem espinho. Em $L$. zellibori o protórax é avermelhado e os ápices dos élitros têm espinho no ângulo externo.

Etimologia. Tupi, kuá = cintura; iuba = amarelo, alusivo à listra transversal dos élitros.

\section{NOVOS REGISTROS}

Registramos para Venezuela, Amazonas, Surumoni, as espécies - Cerambycinae: Neoeme annulicornis (Buquet, 1857) (Oemini); Gnomidolon biarcuatum (White, 1855) (Ibidionini); Isthmiade carinifrons Zajciw, 1972, Rhinotragus lucasii Thomson, 1860 (Rhinotragini); Mecometopus flavius Bates, 1870, M. latecinctus Bates, 1870 (Clytini); Chrysoprasis aureicollis White, 1853, C. rotundicollis Bates, 1870 (Heteropsini); Coremia plumipes (Pallas, 1772), Cosmisoma debile Monné \& Magno, 1988, C. violaceum Zajciw, 1962 (Rhopalophorini); Chlorida curta Thomson, 1857 (Torneutini); Praxithea borgmeieri Lane, 1938 (Torneutini); Phoenidnus lissonotoides Pascoe, 1866 (Trachyderini). Lamiinae, Onciderini: Lochmaeocles callidryas (Bates, 1865); Oncideres gutturator (Fabricius, 1775); O. manauara Martins \& Galileo, 1995; O. satyra Bates, 1865. Os espécimens identificados encontram-se depositados no FAUV, MZSP e MCNZ.

Agradecimentos. A Antonio Santos-Silva (MZSP) pela execução das fotografias.

\section{REFERÊNCIAS}

Monné, M. A. \& S. A. Fragoso. 1996. Sobre Eriphus Audinet-Serville, 1834 e Athetesis Bates, 1870 (Coleoptera, Cerambycidae, Cerambycinae, Trachyderini). Revista Brasileira de Entomologia 40(1): 113-120.

Monné, M. A. \& F. T. Hovore. 2003. Checklist of the Cerambycidae and Disteniidae (Coleoptera) of the Western Hemisphere. Part 1. Parandrinae throught Lepturinae. Eletronic Version, 2002.1 (www.hovore.com), 165 p. 